\title{
Operating the Portable Seismic Pavement Analyzer
}

Haley P. Bell

December 2006

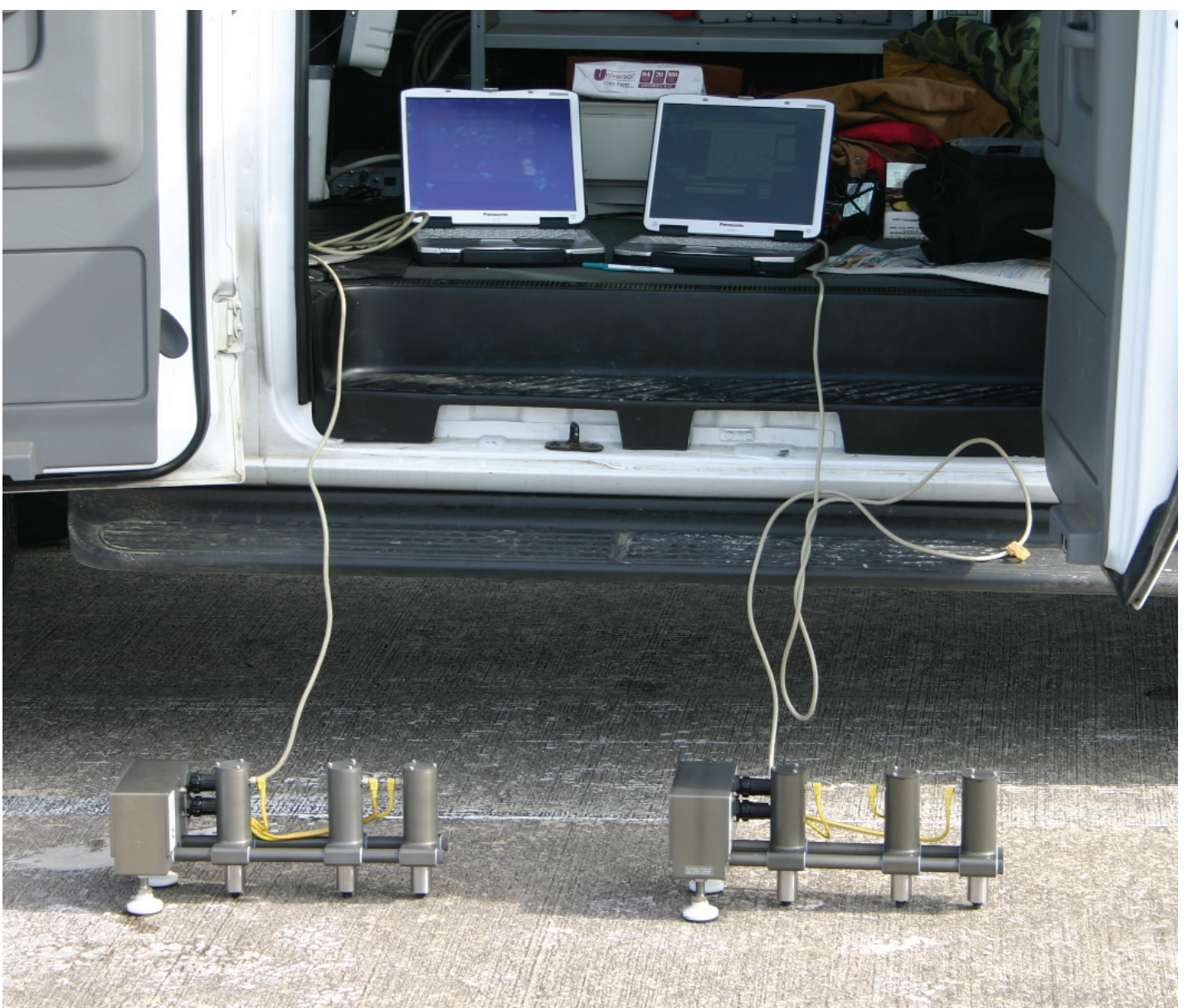




\section{Operating the Portable Seismic Pavement Analyzer}

Haley P. Bell

Geotechnical and Structures Laboratory

U.S. Army Engineer Research and Development Center

3909 Halls Ferry Road

Vicksburg, MS 39180-6199

Final report

Approved for public release; distribution is unlimited.

Prepared for Headquarters, Air Force Civil Engineer Support Agency

139 Barnes Avenue, Suite 1

Tyndall Air Force Base, FL 32403-5319 


\begin{abstract}
The portable seismic pavement analyzer (PSPA) is a nondestructive testing device that measures the seismic modulus of concrete pavements. This report provides guidance on how to operate the PSPA including (a) general use and recommendations of the PSPA, (b) processing data measured from the PSPA, (c) step-by-step instructions for replacing the batteries in the PSPA, (d) step-by-step instructions for removing and replacing the rubber pads on the bottom of the receivers and the source of the PSPA, and (e) troubleshooting.
\end{abstract}

DISCLAIMER: The contents of this report are not to be used for advertising, publication, or promotional purposes. Citation of trade names does not constitute an official endorsement or approval of the use of such commercial products. All product names and trademarks cited are the property of their respective owners. The findings of this report are not to be construed as an official Department of the Army position unless so designated by other authorized documents. 


\section{Contents}

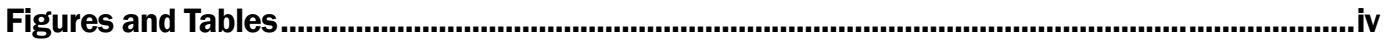

Preface

Unit Conversion Factors.........................................................................................................................vi

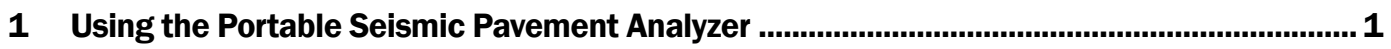

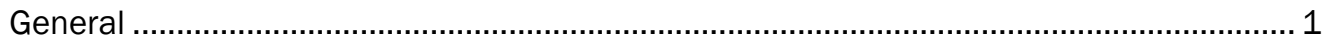

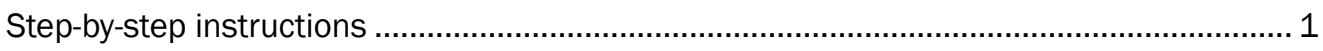

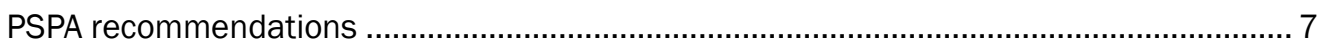

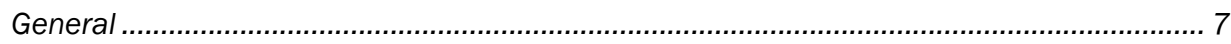

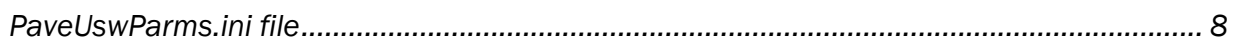

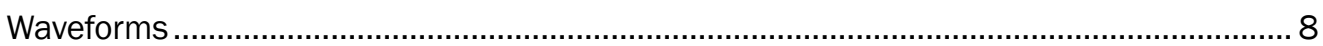

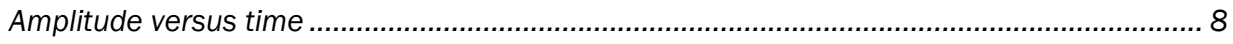

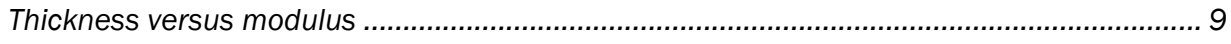

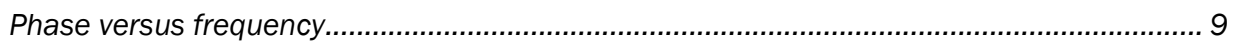

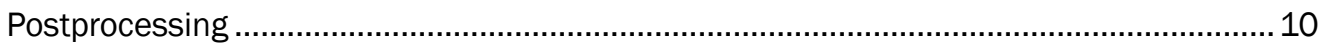

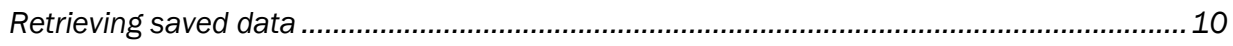

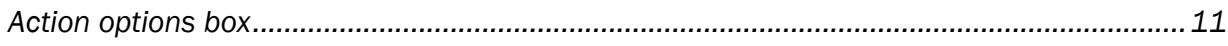

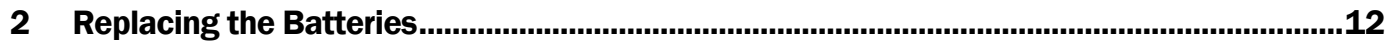

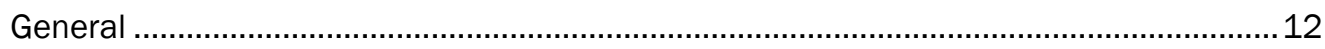

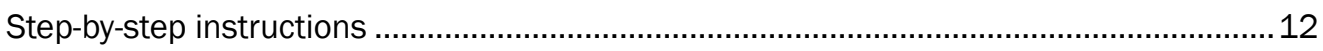

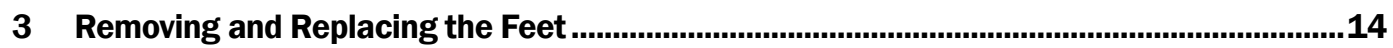

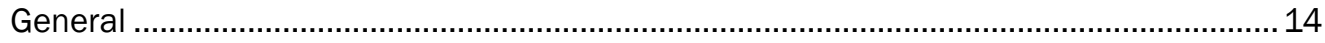

Step-by-step instructions ................................................................................... 15

4 Troubleshooting

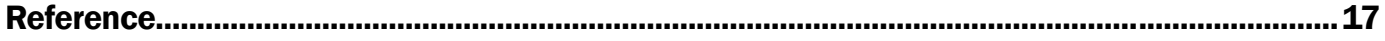

Report Documentation Page 


\section{Figures and Tables}

\section{Figures}

Figure 1. Components of the PSPA............................................................................................ 1

Figure 2. Display in PSPA Status box........................................................................................... 2

Figure 3. Instrument tab showing the serial number and the spacing lengths. ................................ 3

Figure 4. Correct options to select on the Setup Options tab................................................................ 4

Figure 5. Start Options tab....................................................................................................... 4

Figure 6. Options for setting the pavement properties................................................................. 5

Figure 7. Action Summary box............................................................................................... 7

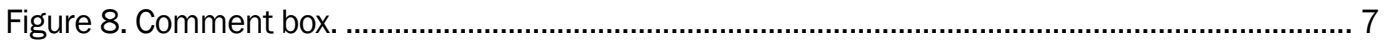

Figure 9. Appropriate amplitude versus time waveforms.............................................................. 9

Figure 10. A thickness versus Young's modulus plot. ................................................................. 10

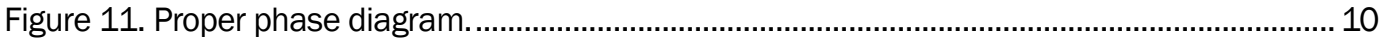

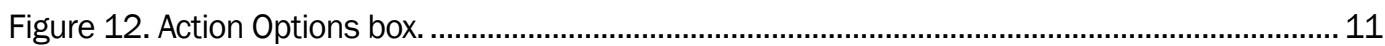

Figure 13. PSPA batteries.................................................................................................... 12

Figure 14. Worn rubber pad on the bottom of the source. ............................................................ 14

Figure 15. Suggested tools for removing and replacing the rubber pads on the feet of the PSPA

\section{Tables}

Table 1. PaveUswParms.ini settings........................................................................................ 8

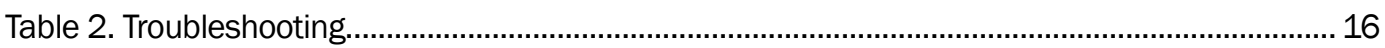




\section{Preface}

The manual presented herein was sponsored by Headquarters, Air Force Civil Engineer Support Agency, Tyndall Air Force Base, Florida.

Personnel of the U.S. Army Engineer Research and Development Center (ERDC), Geotechnical and Structures Laboratory (GSL), Vicksburg, MS, prepared this publication. Haley P. Bell prepared this publication under the supervision of Don R. Alexander, Chief, APB; Dr. Albert J. Bush III, Chief, Engineering Systems and Materials Division; Dr. William P. Grogan, Deputy Director, GSL; and Dr. David W. Pittman, Director, GSL.

COL Richard B. Jenkins was Commander and Executive Director of ERDC. Dr. James R. Houston was Director.

Recommended changes for improving this publication in content and/or format should be submitted on DA Form 2028 (Recommended Changes to Publications and Blank Forms) and forwarded to Headquarters, U.S. Army Corps of Engineers, ATTN: CECW-EW, Kingman Bldg., Rm. 321, 7701 Telegraph Road, Alexandria, VA 22315. 


\section{Unit Conversion Factors}

Non-SI units of measure used in this report can be converted to SI units as follows:

\begin{tabular}{||l|c|l||}
\hline \hline Multiply & By & To Obtain \\
\hline \hline degrees Fahrenheit & $(\mathrm{F}-32) / 1.8$ & degrees Celsius \\
\hline feet & 0.3048 & meters \\
\hline inches & 0.0254 & meters \\
\hline kips (force) per square inch & 6.894757 & megapascals \\
\hline pounds (force) per square inch & 6.894757 & kilopascals \\
\hline
\end{tabular}




\section{Using the Portable Seismic Pavement Analyzer}

\section{General}

The portable seismic pavement analyzer (PSPA) is a simple and nondestructive device that rapidly measures Young's modulus via ultrasonic surface waves. Tests can be performed in less than $30 \mathrm{sec}$, and a user can be trained to operate the device in less than 1 day. The PSPA was developed to provide a means for estimating the in situ seismic modulus of portland cement concrete (PCC) and asphalt concrete (AC) pavements. Additional strength parameters necessary for structural pavement evaluations have been correlated with the PSPA results. Figure 1 shows the various components of the device.

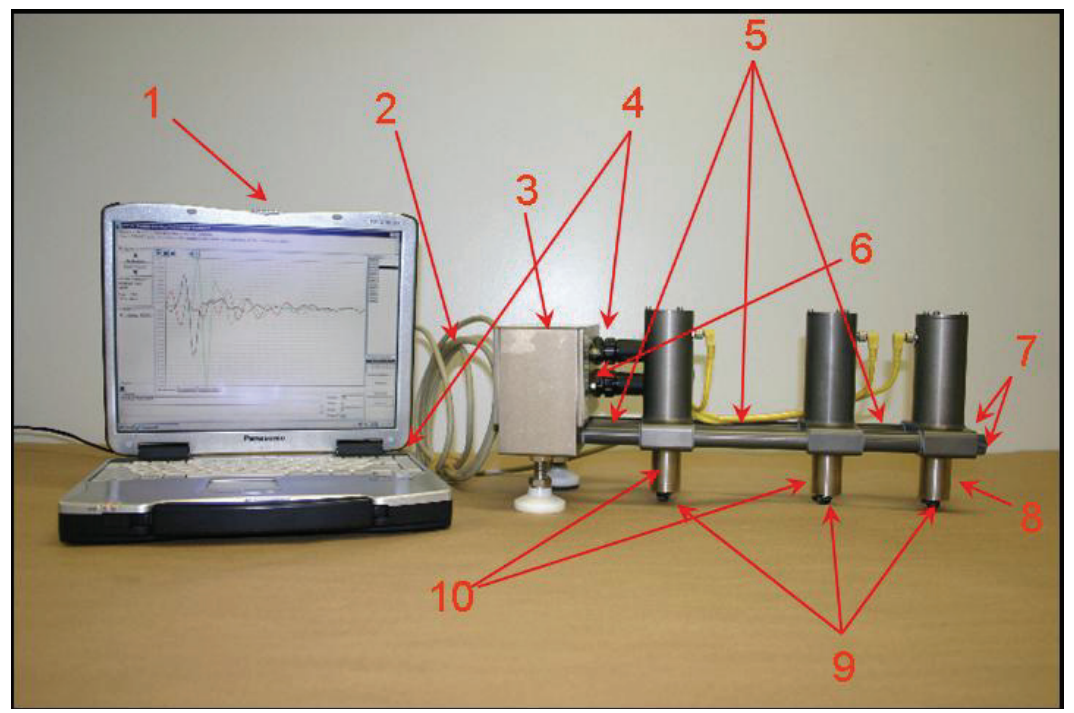

1. Laptop computer

2. Data cable

3. Electronics box

4. Cable connectors

5. Extension rods

6. On/off switch

7. Knobs

8. Source

9. Rubber feet

10. Receivers

Figure 1. Components of the PSPA.

\section{Step-by-step instructions}

1. Install the SpaManager software on a laptop computer (if this has not been done already).

2. Make sure the sensor spacing, on the PSPA, between the receivers is at 4 in. (use the shorter extension rods) if the concrete pavement is equal to or less than 6 in. thick, or make sure the sensor spacing between the receivers is at $6 \mathrm{in}$. (use the longer extension rods) if the concrete pavement is greater than 6 in. thick. To change the spacings so that the 
required distance between the receivers is accomplished, simply swap the extension rods next to the electronics box with the extension rods between the two receivers.

2.1. Remove the two small knobs (screws) at the end (near the source, level with the extension rods) of the PSPA.

2.2. Pull off the source.

2.3. Remove the extension rods located between the receiver and the source, and pull off the receiver next to the source.

2.4. Remove the extension rods located between the two receivers, and pull off the far receiver.

2.5. Remove the extension rods from the electronics box.

2.6. Swap the extension rods next to the electronics box with the rods between the receivers so that the required length between the receivers is accomplished. Slide the receivers and the source back into place.

2.7. Tighten the knobs back on.

3. Plug the round end of the cable into the top round cable port on the PSPA electronics box, and plug the other end into the printer cable port on the back of the laptop computer.

4. Turn the PSPA on by flipping the switch on the electronics box away from the cable connectors (toward the center of the electronics box).

5. Open up the SpaManager program on the laptop computer.

6. The PSPA Status box will appear; this box displays the remaining percentage of battery life and the approximate number of samples that can be performed on the batteries as shown in Figure 2. Click anywhere inside the PSPA Status box.

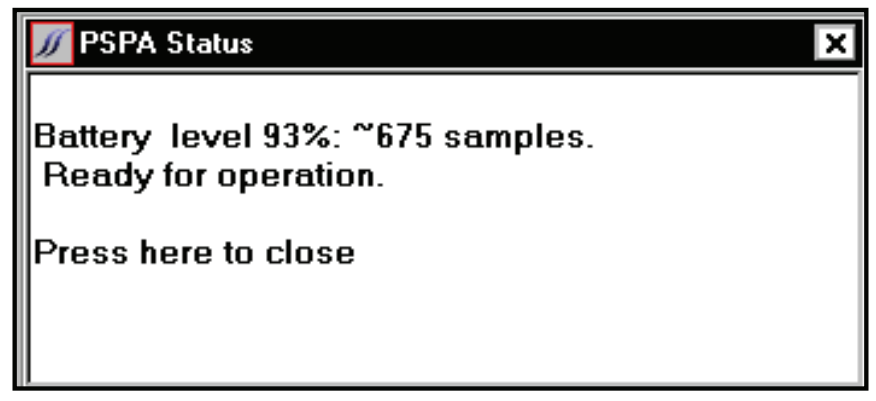

Figure 2. Display in the PSPA Status box.

7. Select the Instrument tab (Figure 3) to make sure the serial number of the PSPA and the spacing lengths match those shown on the PSPA. The spacing lengths shown are the distances between the source and each 
receiver. The serial numbers are located on the electronics box, the receivers, and the source. If any changes are made in the computer, select Save.

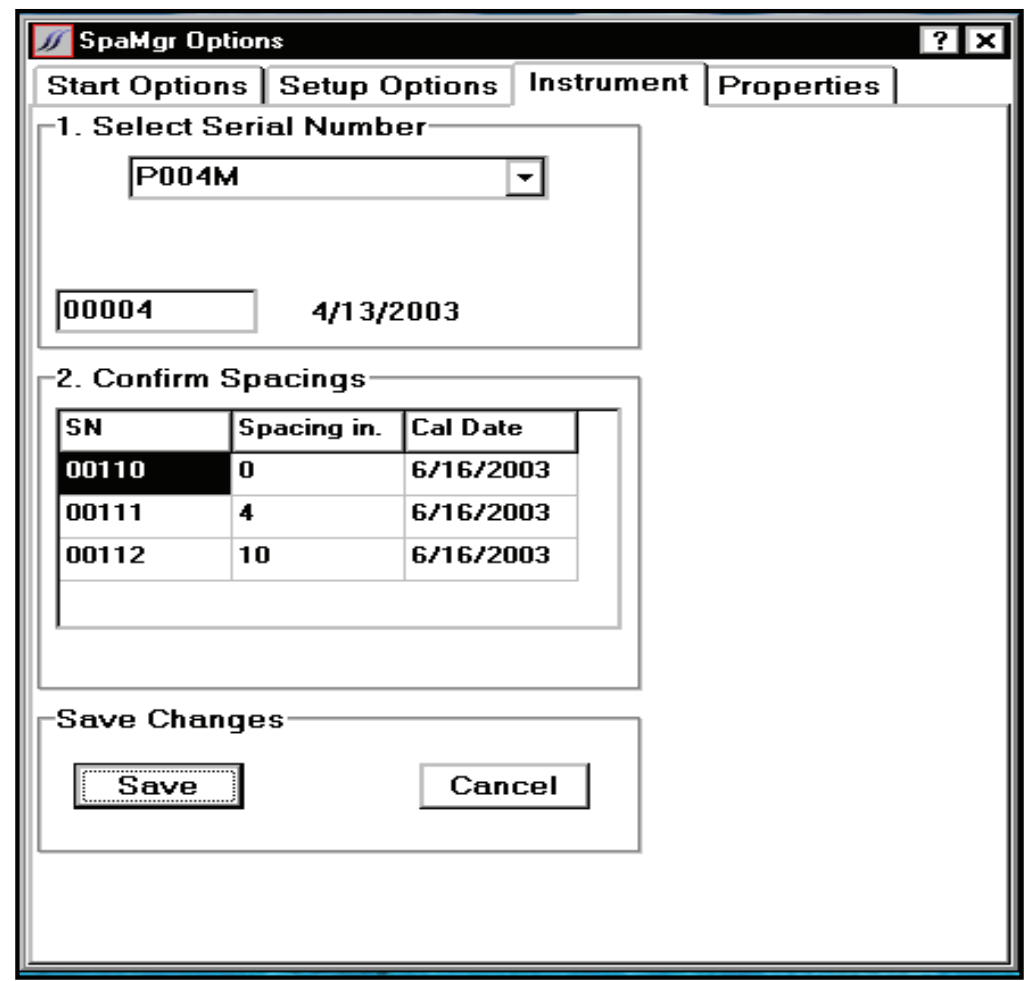

Figure 3. Instrument tab showing the serial number and the spacing lengths.

8. Select the Setup Options tab to make sure the Reduction, Analysis, and Report options are set, as shown in Figure 4.

9. Return to the Start Options tab.

10. Select START NEW APPLICATION if starting at a new test site, or select USE LAST PROJECT if returning to a previous test site (see Figure 5).

o If using the last project, skip to step 21.

11. Highlight PCC-AC Modulus (This allows the user to enter in known or estimated thickness.)

12. Select Save Application.

13. Select New Project, and type in the name of the project in the highlighted box.

14. Select Save Project.

15. Type the name of the site in the highlighted box.

16. Select Save Site. 


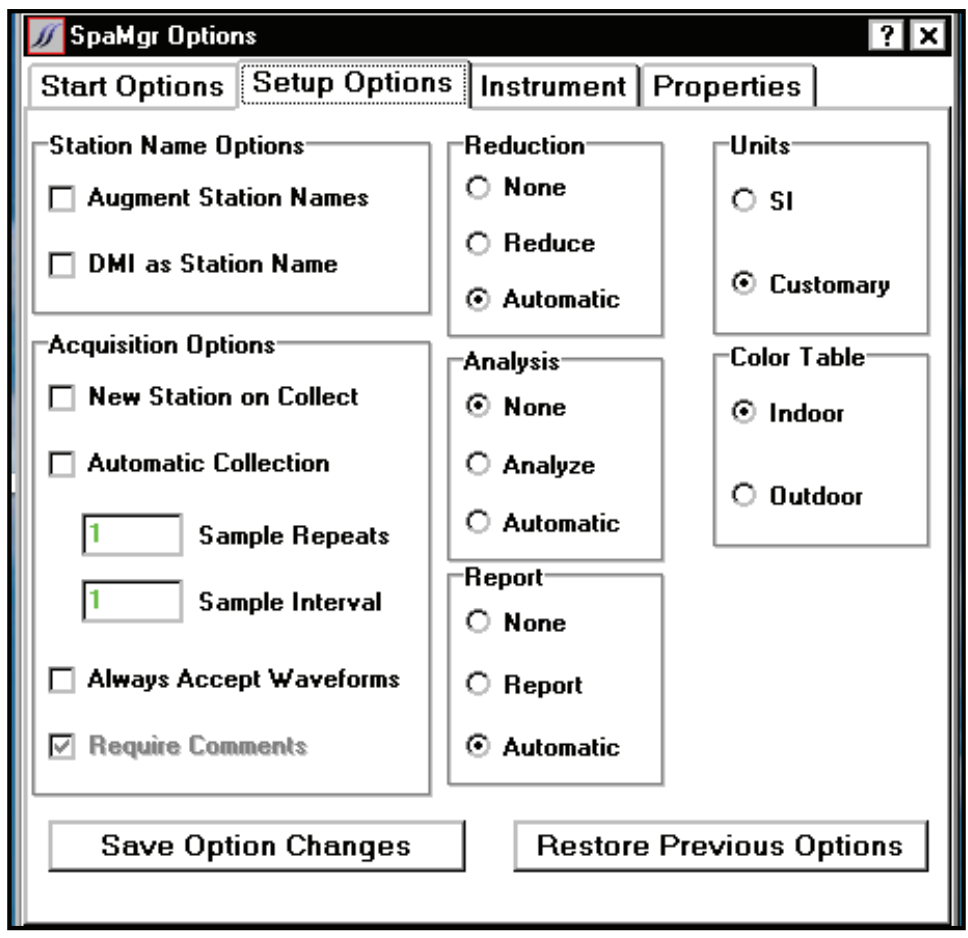

Figure 4. Correct options to select on the Setup Options tab.

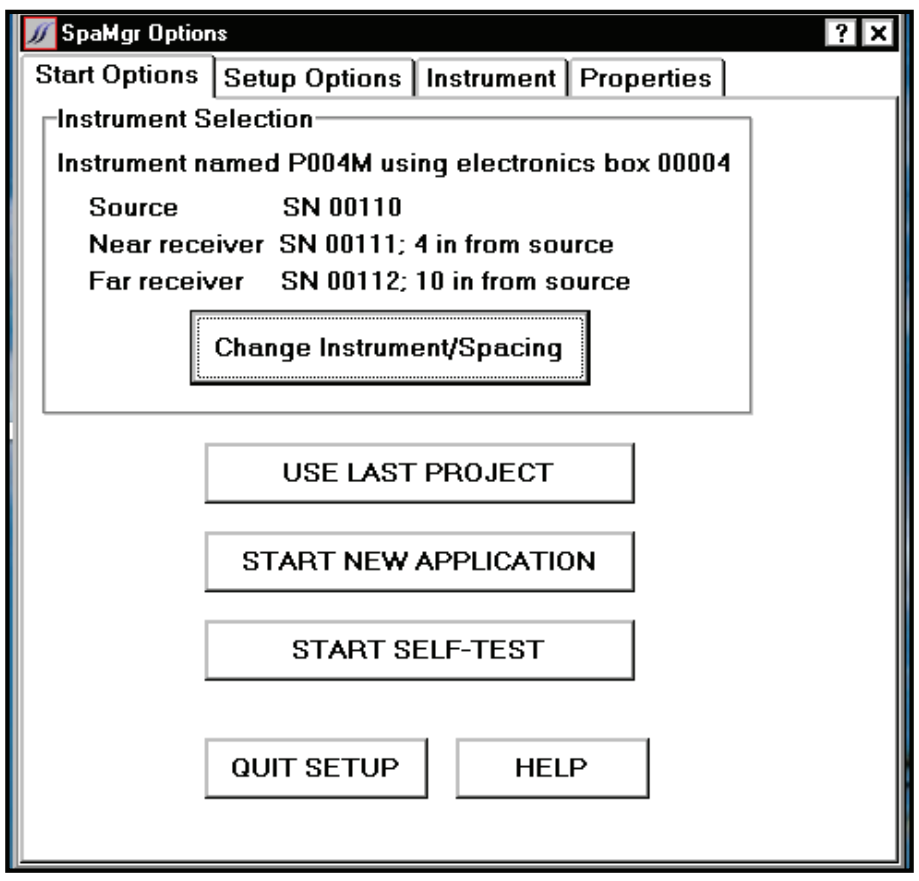

Figure 5. Start Options tab. 
17. Set the properties to the appropriate conditions (i.e., AC or PCC, cured or fresh, etc.). Figure 6 shows the display for the properties menu.

17.1. Set the thickness.

a. If the thickness of the concrete is above 12 in., then type 12.

b. If the thickness of the concrete is below 12 in., then type the appropriate thickness.

17.2. Select the PCC concrete property to be Good if it is fairly new and there are no visual distresses, and select the concrete property to be Poor if the pavement is old or appears to be in bad condition. Otherwise, select Fair.

17.3. Select the PCC concrete property as Fresh if it is less than 3 days old. Otherwise, select Cured.

17.4. For the AC concrete pavements, select the temperature property to be Hot if the temperature of the pavement is greater than $130{ }^{\circ} \mathrm{F}\left(54^{\circ} \mathrm{C}\right)$, and select the temperature property to be Cold if the temperature of the pavement is near freezing. Otherwise, select Mild. When in doubt, err toward the side of the warmer condition.

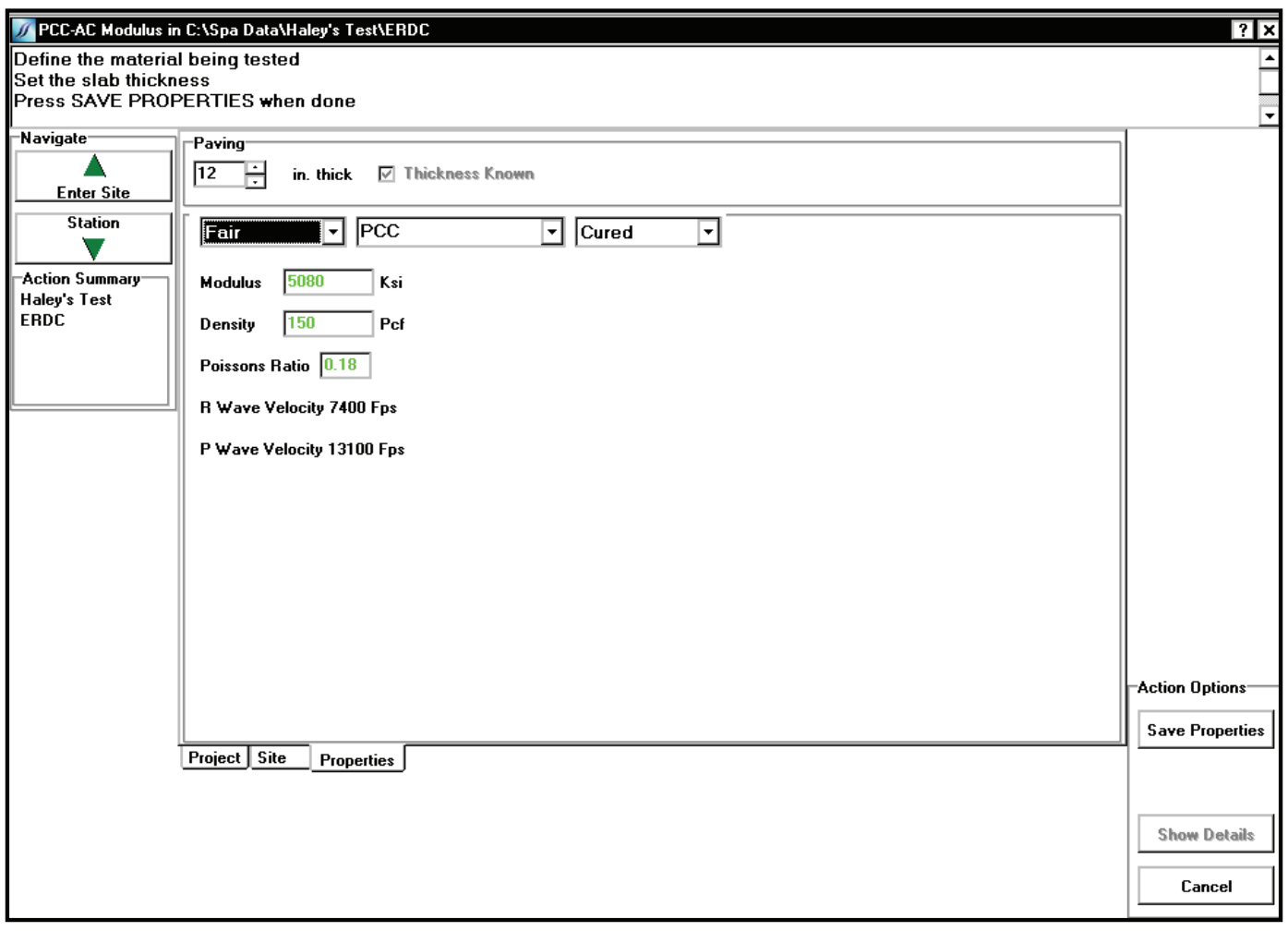

Figure 6. Options for setting the pavement properties. 
17.5. Leave the Modulus, Density, and Poisson's Ratio as its default.

18. Select Save Properties.

19. Type in the name of the file.

20. Select Save.

21. Place the PSPA at the desired testing location.

21.1. Make sure that the feet of the receivers and the source are completely touching the concrete pavement and are perfectly vertical by pushing down on the electronics box and the source and pulling down on the receivers.

NOTE: Be careful not to twist the shafts of the receivers or the source because the wires inside them may break.

21.2. Avoid testing over cracks in the concrete pavements.

21.3. Place the PSPA at least one PSPA length away from joints and parallel to the grooves.

22. Select New Station.

23. Type in the desired station, or leave it at its default.

24. Select Collect New.

25. Select Accept after the PSPA has run the test and the waveforms have appeared on the screen. Select Reject if you choose to not accept the current test.

26. Select Repeat Collect if more tests in the same location (station) are desired. It is recommended to conduct at least three repeats at each station.

27. Move to the next test location, and repeat steps 21-26.

28. Repeat steps 17-18 when necessary.

29. Close the SpaManager program when testing is complete. The data will automatically be saved.

NOTE: Often, air pressure builds up in the receivers on the PSPA. The two knobs on the end of the PSPA (by the source, level with the extension rods) may need to be slightly loosened occasionally to release this air pressure. The PSPA will properly operate with the knobs slightly loosened if the user chooses to do so.

o The Action Summary box (Figure 7) shown in the upper left corner on the laptop computer screen displays the name of the 
project, the name of the site, and certain pavement properties that were selected.

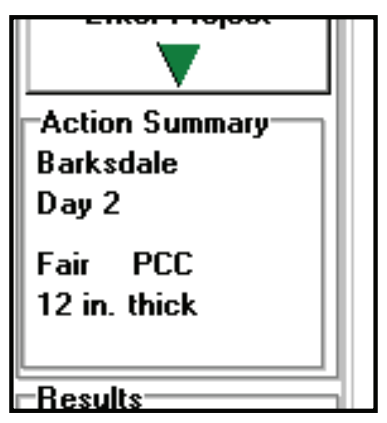

Figure 7. Action

Summary box.

- The Comment box (Figure 8) on the bottom of the laptop computer screen displays the project and site names and allows the user to type in any notes before or during testing. The notes will automatically be saved.

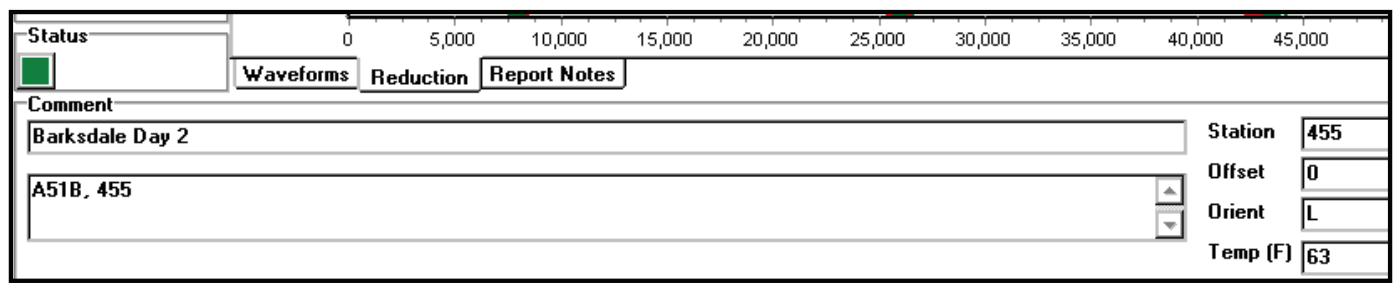

Figure 8. Comment box.

\section{PSPA recommendations}

\section{General}

Operate the PSPA at least four times in a feature for a 95\% confidence. It is suggested to do at least three test repeats at each location (station).

Use the following correlation when determining flexural strength from the PSPA modulus:

$$
\text { Flexural strength, psi }=0.12{ }^{*} E_{P S P A}
$$

where

$\mathrm{E}_{\mathrm{PSPA}}=$ Young's modulus determined from the PSPA, ksi. 


\section{PaveUswParms.ini file}

The PaveUswParms.ini file, located in c: $\backslash$ ProgramFiles $\backslash$ GrdSpa3.2 $\backslash$

PaveUswParms.ini, controls the ultrasonic wave reduction attributes. The user can modify the parameters for special applications if desired. See Table 1 for the details of the PaveUswParms.ini file.

Table 1. PaveUswParms.ini settings.

\begin{tabular}{|l|l|}
\hline Parameter & Definition \\
\hline 0 & Absolute minimum analysis frequency $(\mathrm{Hz})$ \\
\hline 50000 & Absolute maximum analysis frequency $(\mathrm{Hz})$ \\
\hline 5 & Smoothing parameter, first pass phase fit \\
\hline 3 & Smoothing parameter, second pass phase fit \\
\hline 25 & Maximum phase (radians) for phase fitting \\
\hline 0.1 & Pass one/Pass two correction allowance \\
\hline 1 & Velocity multiplier for half-space velocity \\
\hline 0.5 & Minimum analysis wavelength, fraction of spacing \\
\hline 2 & Maximum analysis wavelength, fraction of spacing \\
\hline 0 & Full spectrum dump (1), no spectrum dump (0) \\
\hline
\end{tabular}

It is suggested that the parameters be saved as they are in Table 1; however, the minimum analysis wavelength should be set no lower than 0.25 when operating the PSPA on thin pavements (equal to or less than 6 in.), and the minimum analysis wavelength should be set at 0.5 when operating the PSPA on thick pavements (greater than 6 in.).

\section{Waveforms}

\section{Amplitude versus time}

The waveforms on the amplitude versus time plot should display periodic oscillations, and the amplitude spectrum should have a single dominant peak. The red curve should be small, and the black and green curves should be tall and sharp. The amplitude of all three lines should decrease with time. The red curve corresponds to the source, while the black and green curves correspond to the receiver near the source and the receiver near the electronics box, respectively. Figure 9 shows a screen shot of how the waveforms should appear.

All waveforms may not appear exactly as those shown in Figure 9, but they should look similar. 


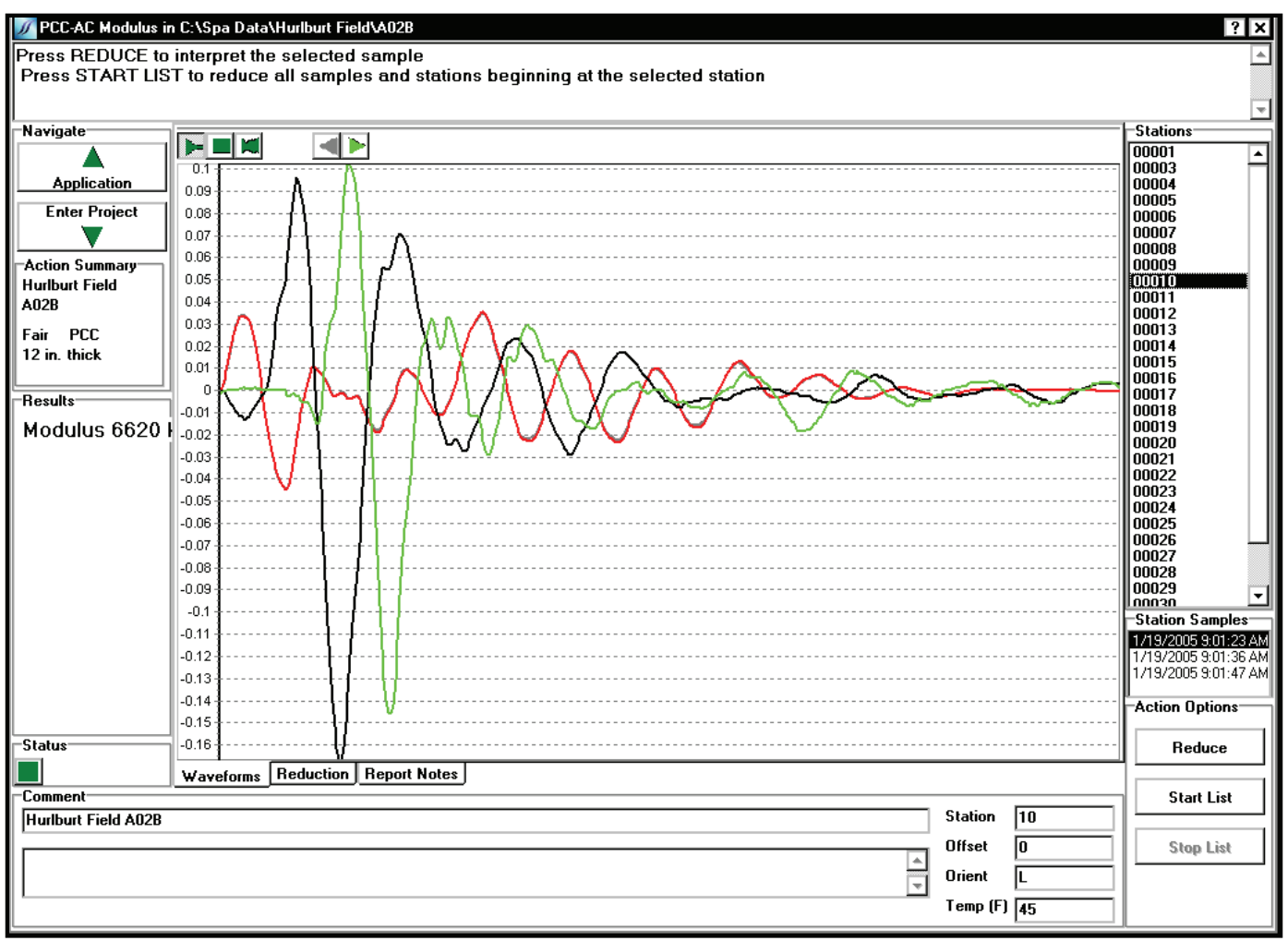

Figure 9. Appropriate amplitude versus time waveforms.

\section{Thickness versus modulus}

The thickness versus modulus plot shows the strength of the pavement through the depth of the surface layer. The vertical red bar indicates the average modulus value measured throughout the thickness of the pavement, and this is the value that is used for the analysis. The plot shown in Figure 10 for a 12-in.-thick concrete pavement indicates that the pavement is stronger at the surface and weaker toward the base.

\section{Phase versus frequency}

The phase diagram, located under the thickness versus modulus plot, should show a red line and a green line. The green line is the raw data, and the red line is the best fit line. They should be on top of each other or at least close to each other while under the yellow horizontal bar. The yellow bar indicates the data being used to compute the wave velocity. If desired, the yellow bar can be lengthened or shortened by clicking the computer mouse on the right end of the bar and moving it to the left or right.

Figure 11 shows how the lines in the phase diagram should appear while under the yellow bar. 


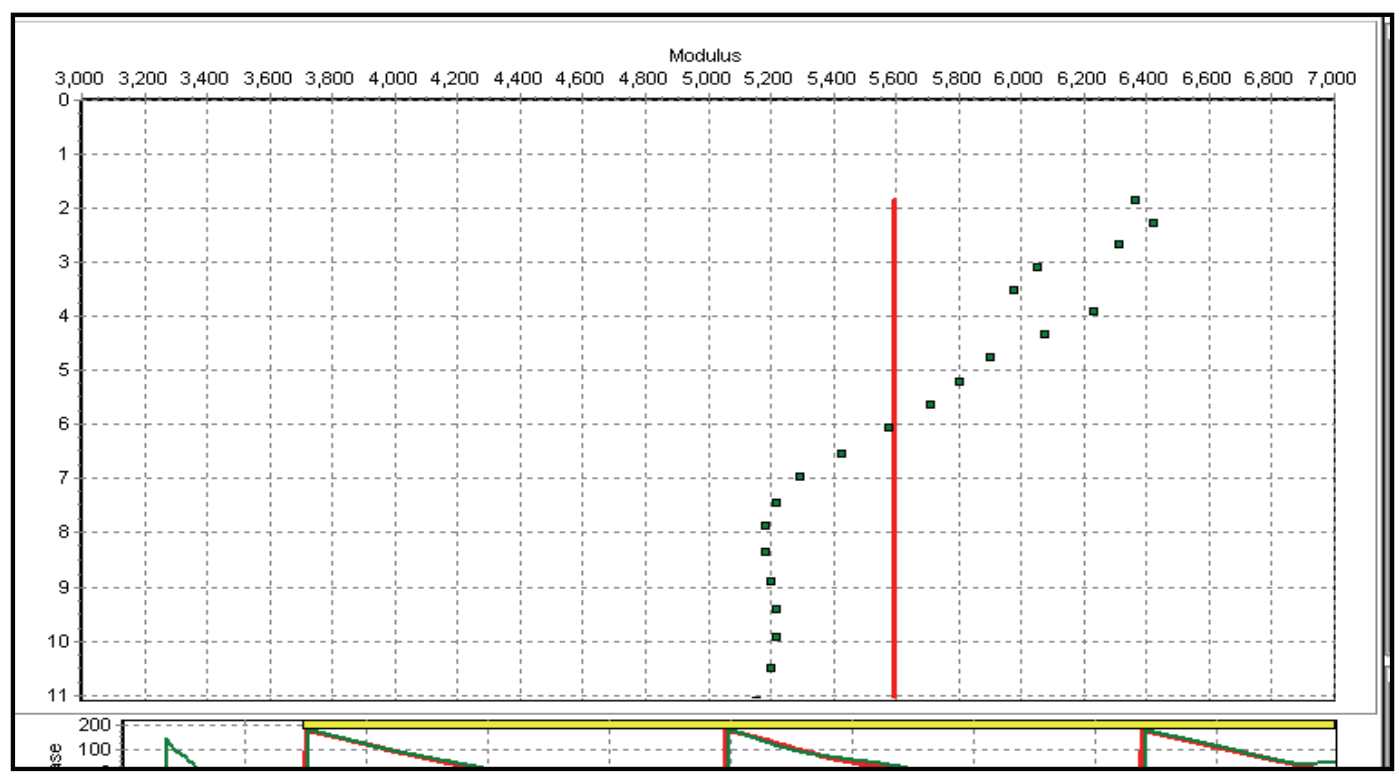

Figure 10. A thickness (inches) versus Young's modulus (ksi) plot.

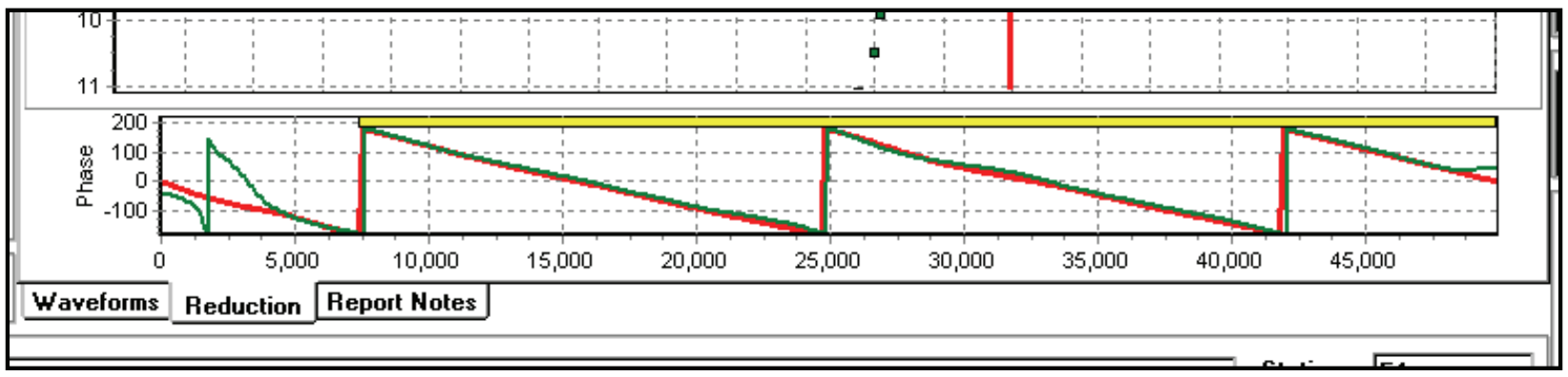

Figure 11. A proper phase diagram.

\section{Postprocessing}

\section{Retrieving saved data}

All data are automatically saved and located in the [SpaData] folder. After testing, saved data can be reprocessed if necessary. Saved data can be imported or manually input into Microsoft Excel for analyzing.

A design modulus must be utilized when the PSPA is used on AC pavements (Nazarian et al. 2005). The AC design modulus is corrected to a temperature of $77^{\circ} \mathrm{F}$ and a design frequency of $15 \mathrm{~Hz}$ using Equation 2.

$$
E_{77^{\circ} F}=\frac{E_{P S P A}}{\left[\left(-0.0109 *\left((T-32) * \frac{5}{9}\right)+1.2627\right) *(3.2)\right]}
$$


where:

$$
\begin{aligned}
E_{77^{\circ} F} & =\text { design modulus of the AC pavement, ksi } \\
E_{P S P A} & =\text { modulus measured from the PSPA, ksi } \\
T & =\text { AC pavement temperature, }{ }^{\circ} \mathrm{F}
\end{aligned}
$$

The design modulus should be incorporated with the data in your Microsoft Excel spreadsheet. $\mathrm{E}_{77^{\circ} \mathrm{F}}$ is the corrected AC modulus value to use for recording or analyzing.

\section{Action options box}

The Reduce, Start List, and Stop List buttons are located in the Action Options box in the SpaManager program. Figure 12 shows the Action Options box. If any station properties in the SpaManager program are changed and saved after the testing is complete, the Reduce button on the SpaManager laptop computer screen allows the user to reprocess the data with the corrected properties. The Start List button reduces all data automatically starting with the station that is highlighted. The Stop List button stops the automatic reducing of the data.

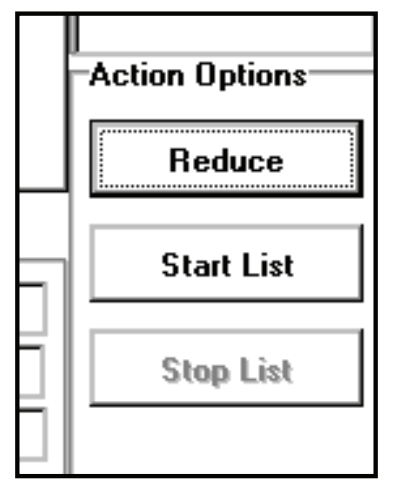

Figure 12. Action Options box. 


\section{Replacing the Batteries}

\section{General}

The battery life of the PSPA is approximately 3 to 5 full working days. The percent battery life of the device is given on the initial screen of the laptop computer that is shown when the SpaManager program is first opened. Though not always true, unexplainable waveforms and modulus values are good indicators that the batteries need to be replaced. The PSPA runs on 10 size AA batteries located in the electronics box as shown in Figure 13.

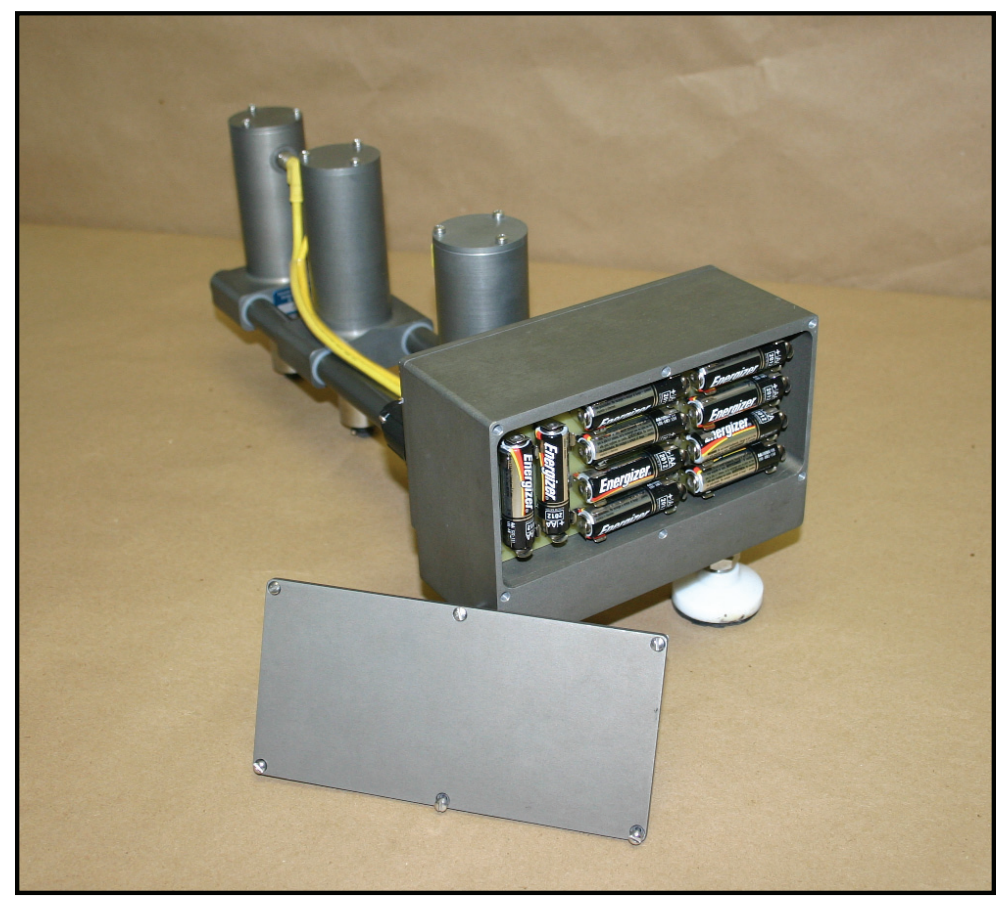

Figure 13. PSPA batteries.

\section{Step-by-step instructions}

1. Unscrew the cover on the PSPA electronics box.

2. Carefully pop out the old batteries while being conscious of the delicate prongs.

3. Place the new batteries in the pronged slots.

4. Screw the cover back on the PSPA electronics box. 
If rechargeable batteries are used in place of regular batteries, they can be charged using the adaptor that comes with the PSPA. Simply plug the round end of the adaptor cable into the small round cable connector located on the electronics box of the PSPA, and plug the other end of the adaptor into an electrical outlet. The batteries should be charged for approximately 6 to $8 \mathrm{hr}$. 


\section{Removing and Replacing the Feet}

\section{General}

On the bottom of the receivers and the source are rubber cushions that cover the metal feet of the PSPA. The roughness of the concrete pavements can wear down and tear the rubber cushions, exposing the metal on the bottom of the receivers and the source. See Figure 14 below.

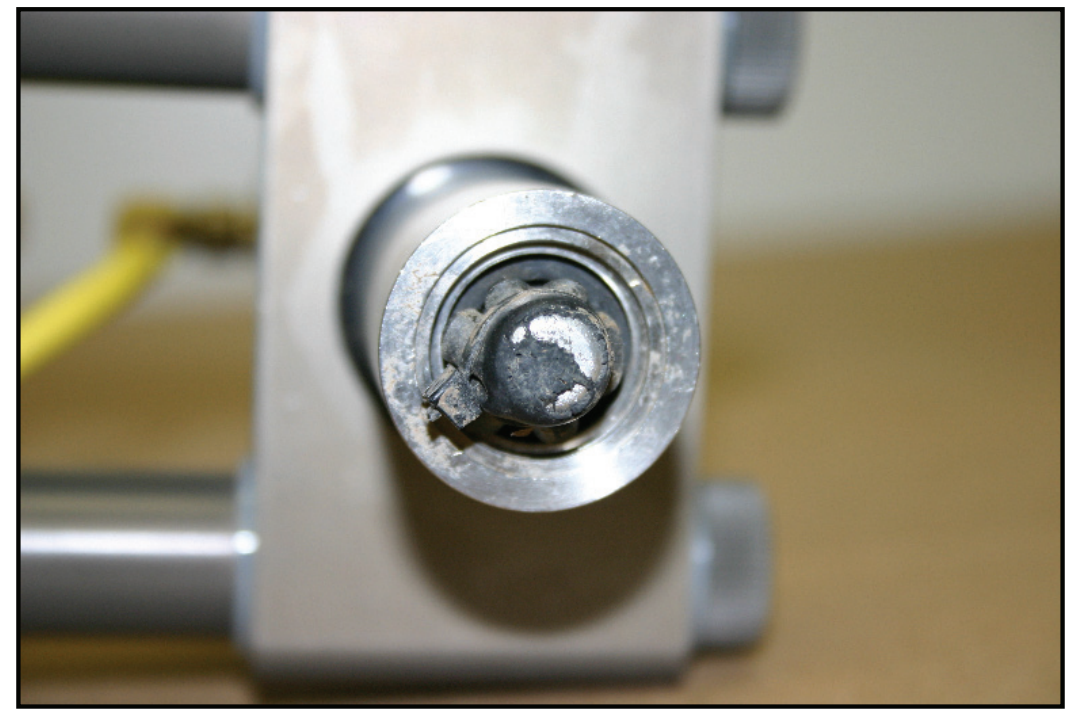

Figure 14. Worn rubber pad on the bottom of the source.

Proper and periodic changing of the feet is relatively simple and allows the PSPA to provide accurate measurements. The feet of the PSPA should be checked at least at the end of every work day, but will most likely not have to be changed until after approximately 2 full days of working in the field. The rubber pads are made from 1-in.-diam pieces of rubber cut from the inner tube of a bicycle tire, and they are secured with 4-in. cable ties. Figure 15 shows the tools recommended for removing and replacing the rubber pads. 


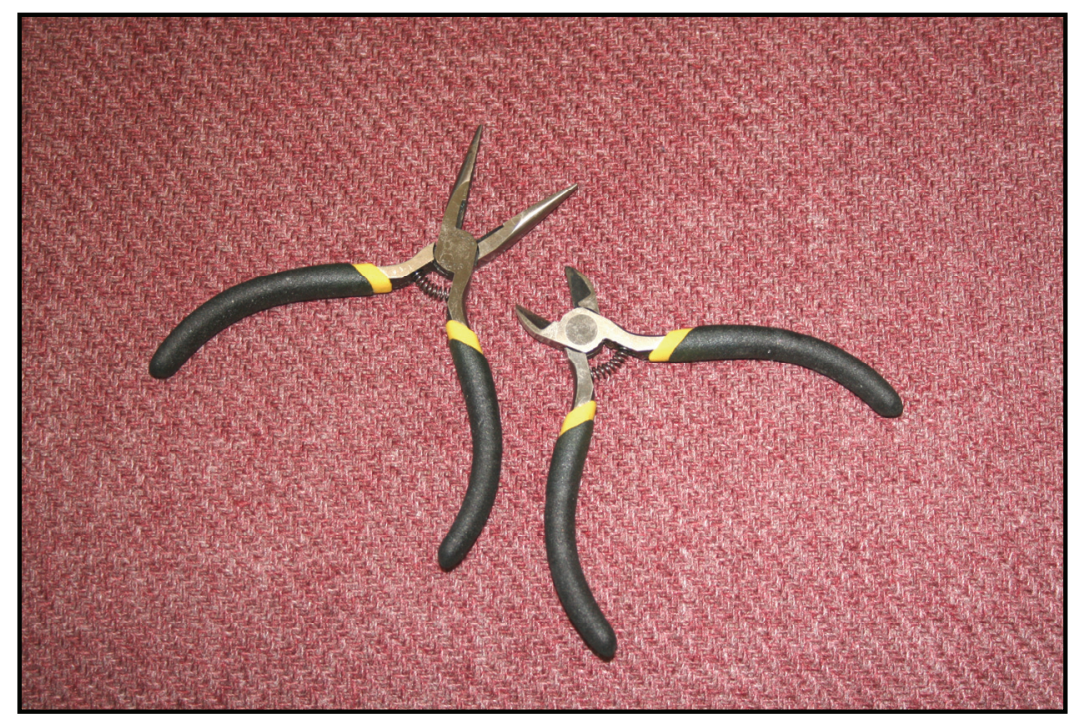

Figure 15. Suggested tools for removing and replacing the rubber pads on the feet of the PSPA.

\section{Step-by-step instructions}

1. Remove the worn rubber pads by clipping the plastic cable ties with a pair of wire cutters.

2. Begin assembling the cable tie into the circular shape, leaving some slack.

3. Place the round rubber cushion over the metal part, and slide the plastic cable tie on until it is over the head of the metal foot.

4. Pull the plastic cable tie tight with needle-nose pliers until the rubber pad is securely in place.

5. Using the pliers, pull the outside of the rubber pad to make sure it is laying flat on the metal.

6. Clip the remaining tail of the plastic cable tie with the wire cutters.

7. Repeat steps 1 through 6 for the two remaining feet. 


\section{Troubleshooting}

\section{If the PSPA is not performing to expectations, try these simple suggestions shown in Table 2.}

Table 2. Troubleshooting.

\begin{tabular}{|l|l|}
\hline Problem & Suggestion \\
\hline $\begin{array}{l}\text { Modulus values and/or } \\
\text { waveforms are suspect. }\end{array}$ & $\begin{array}{l}\text { Make sure the PSPA is not being tested over a crack in the concrete } \\
\text { pavement. } \\
\text { Make sure the feet of the PSPA are perfectly vertical and are making } \\
\text { good, clean contact with the concrete pavement. } \\
\text { Check for any wear and tear to the rubber pads on the feet of the } \\
\text { PSPA. } \\
\text { Make sure the properties are set correctly (i.e., hardware, pavement } \\
\text { conditions, etc.). } \\
\text { Check the percent battery life of the PSPA. } \\
\text { Wires inside the receivers and/or the source may be broken. Send to } \\
\text { the manufacturer for repairs. }\end{array}$ \\
\hline $\begin{array}{l}\text { Action Failure Message on the } \\
\text { laptop computer indicates that } \\
\text { the battery test failed. }\end{array}$ & $\begin{array}{l}\text { Make sure the cable is properly and securely inserted in the } \\
\text { connectors on the electronics box and the laptop computer. }\end{array}$ \\
\hline $\begin{array}{l}\text { Inconsistent modulus values at } \\
\text { the same testing site. }\end{array}$ & $\begin{array}{l}\text { Wires inside the receivers and/or the source may be broken. Send to } \\
\text { the manufacturer for repairs. }\end{array}$ \\
\hline $\begin{array}{l}\text { A red dot appears above the } \\
\text { measured modulus value on the } \\
\text { laptop computer. }\end{array}$ & $\begin{array}{l}\text { The instrument serial number was not analyzed with the calibration } \\
\text { data. This will not affect the measured modulus values, but it will } \\
\text { affect the thickness estimates. Make sure the correct hardware is } \\
\text { selected. }\end{array}$ \\
\hline pavement. & $\begin{array}{l}\text { Make sure the cables are properly and securely connected. } \\
\text { Make sure the PSPA is powered on. }\end{array}$ \\
\hline
\end{tabular}




\section{Reference}

Nazarian, S., V. Tandon, and D. Yuan. 2005. Mechanistic quality management of asphalt concrete layers with seismic methods. Journal of ASTM International 2(8).

West Conshohocken, PA: American Society for Testing and Materials. 


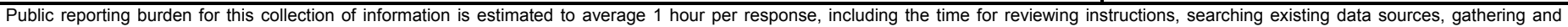

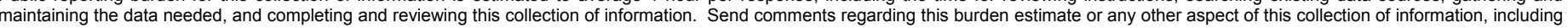

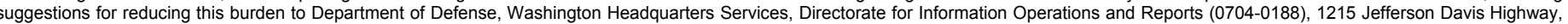

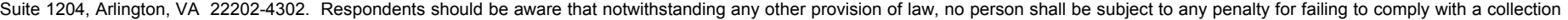
of information if it does not display a currently valid OMB control number. PLEASE DO NOT RETURN YOUR FORM TO THE ABOVE ADDRESS.
1. REPORT DATE (DD-MM-YYYY)
2. REPORT TYPE
December 2006
Final report

4. TITLE AND SUBTITLE

Operating the Portable Seismic Pavement Analyzer

3. DATES COVERED (From - To)

5a. CONTRACT NUMBER

5b. GRANT NUMBER

5c. PROGRAM ELEMENT NUMBER

6. AUTHOR(S)

Haley P. Bell

5d. PROJECT NUMBER

5e. TASK NUMBER

5f. WORK UNIT NUMBER

MIPR 3FDPWRPM10

7. PERFORMING ORGANIZATION NAME(S) AND ADDRESS(ES)

8. PERFORMING ORGANIZATION REPORT NUMBER

Geotechnical and Structures Laboratory

3909 Halls Ferry Road

ERDC/GSL SR-06-9

Vicksburg, MS 39180-6199

9. SPONSORING/MONITORING AGENCY NAME(S) AND ADDRESS(ES)

10. SPONSOR/MONITOR'S ACRONYM(S)

Headquarters, Air Force Civil Engineer Support Agency

139 Barnes Avenue, Suite 1

Tyndall Air Force Base, FL 32403-5319

11. SPONSOR/MONITOR'S REPORT NUMBER(S)

\section{DISTRIBUTION/AVAILABILITY STATEMENT}

Approved for public release; distribution is unlimited.

\section{SUPPLEMENTARY NOTES}

\section{ABSTRACT}

The portable seismic pavement analyzer (PSPA) is a nondestructive testing device that measures the seismic modulus of concrete pavements. This report provides guidance on how to operate the PSPA including (a) general use and recommendations of the PSPA, (b) processing data measured from the PSPA, (c) step-by-step instructions for replacing the batteries in the PSPA, (d) stepby-step instructions for removing and replacing the rubber pads on the bottom of the receivers and the source of the PSPA, and

(e) troubleshooting.

\section{SUBJECT TERMS}

Flexural strength

Nondestructive testing
PSPA

Seismic

\begin{tabular}{|c|c|c|}
\hline \multicolumn{3}{|c|}{ 16. SECURITY CLASSIFICATION OF: } \\
\hline a. REPORT & b. ABSTRACT & c. THIS PAGE \\
\hline UNCLASSIFIED & UNCLASSIFIED & UNCLASSIFIED \\
\hline
\end{tabular}

\begin{tabular}{l|l}
\hline 17. LIMITATION & $\begin{array}{l}\text { 18. NUMBER } \\
\text { OF PAGES } \\
\text { OF ABSTRACT }\end{array}$ \\
& 24 \\
\end{tabular}

19a. NAME OF RESPONSIBLE PERSON

19b. TELEPHONE NUMBER (include area code) 